\title{
Accounting
}

\section{Malaysian private entity reporting standard (MPERS) implementation for small and medium enterprises (SMEs)}

\author{
Nurul Nazlia Jamil ${ }^{* *}$ and Siti Nur Ayuni Ruslia
}

${ }^{a}$ Faculty of Economics and Muamalat, Universiti Sains Islam Malaysia

\begin{tabular}{l}
\hline C H R O N I C L E \\
\hline Article history: \\
Received: October 28, 2020 \\
Received in revised format: \\
November 282020 \\
Accepted: December 22, 2020 \\
Available online: \\
December 28, 2020 \\
\hline Keywords: \\
Malaysian Private Entity Reporting \\
Standard (MPERS) \\
Accounting \\
Small and Medium Enterprises \\
(SMEs) \\
Financial Reporting \\
Malaysia
\end{tabular}

\begin{abstract}
A B S T R A C T
Malaysian Private Entity Reporting Standard (MPERS) serves as new reporting framework to private entities and significant milestone to the capital market. The qualification for first-time MPERS adoption is incremental and it is important to prepare in advance for private entities if they intend to move to the MPERS or MFRS framework in the near future. A common question that private entities may ask is how far-reaching or how reliable the current Private Entity Reporting Standards (PERS) Framework is comparable to the new MPERS or MFRS framework. The adoption of MPERS is retrospective. The purpose of the analysis is to analyze the implementation of MPERS on small medium enterprises (SMEs) and how they perceive the implementation. The study covers all sectors of the SME sector, namely services, manufacturing, agriculture, construction, mining and quarrying, and is subdivided into Micro, small and medium and in three categories. These sectors were selected based on the SMEs landscape of Malaysia following the issuance of MPERS on February 14, 2014. There were 55 of SMEs participated in this research by answering the questionnaire. The study evaluated using linear regression and the measures of research are based on the factors described in the literature review, influence the variables. Hence, the SMEs experiences have the potential to make respondent's perception of MPERS also agreeable. The implications of the research highlighted that the implementation of the MPERS still at the infancy level as there are few challenges faced by the SMEs regards to the implementation. Therefore, the regulators and standard setter can identify the challenges and provide appropriate assistance to ensure the financial reports are fairly presented.
\end{abstract}

(C) 2021 by the authors; licensee Growing Science, Canada

\section{Introduction}

Small and Medium Enterprises (SMEs) in Malaysia plays a very significant role for the development of the economy. The fate of Malaysia's economy depends on the accomplishment of small and medium enterprises (SMEs). SMEs is crucial because currently, over 7 million jobs are provided by SMEs to $66.2 \%$ of Malaysia's workforce. $98.5 \%$ of all businesses in Malaysia are SMEs, and in 2019 , the SME sector contributed $38.3 \%$ to the overall gross domestic product (GDP) of the country, $17.3 \%$ to total exports and $66.2 \%$ of overall total employment in 2018 (SME Annual Report, 2018/2019). Nonetheless, SMEs in Malaysia faced a problem to handle with the effects of the Sales and Service Tax (SST) launched on 1 September 2018 to replace the 2014 Good and Services Tax (GST). SMEs also must consider with new minimum wage and now a new financial standard has been introduced called Malaysian Private Entity Reporting Standard (MPERS) to be adopted by SMEs. This change has resulted a mixed reaction between accounting bodies, business owners and the government among the market players. The first international standard issued by the International Accounting Standards Committee (IASC) was the International Accounting Standards (IAS), which was issued from 1973 to 2000 . The IAS was issued to enable the comparison of businesses with companies around the world, to

* Corresponding author.

E-mail address: nurulnazlia@usim.edu.my (N. N. Jamil) 
enhance transparency and accountability in financial reporting, and to facilitate global trade and investment. IAS is the older standards that IFRS replaced and sometimes IFRS is confused with IAS. In 2001, IASB replaced the International Accounting Standards Committee (IASC). The International Financial Reporting Standards (IFRS) and the IFRS Foundation published the International Financial Reporting Standard (IFRS), to be adopted by SEs, on 9 July 2009. Fewer than 35 countries, including Malaysia, are expected to follow IFRS standard (Salin, 2017).

Currently, SMEs can choose between the continuation of the current Private Entity Reporting Standards (PERS) or implementation of the Malaysian Financial Reporting Standards (MFRS) (compulsory for non-private entities other than transitional entities) or the compulsory transfer of SMEs to the new MPERS framework by 1 January 2016. If they need to switch to MPERS or drift to MFRS in the future, it is important for SMEs to prepare in advance as the first-time adoption requirement for MPERS is. Since it is an international accounting standard, the MPERS is seen to provide businesses with the opportunity. In addition, 73 nations, including the Australia, United Kingdom, Hong Kong, Singapore and 14 other countries considering using the standard (IFRS for SMEs) are widely adopting the standard. Thus, MPERS may provide the convergence and comparability of local business with foreign business with a bit of adjustment to the Malaysian business environment. Adoption of MPERS framework is an important step towards preparing private entities or the SMEs to globalization. SMEs will be able to create opportunities and SMEs could facing enormous challenges through the globalization. It is important and relevant that the SMEs in Malaysia adopted a global financing reporting language that is not only up to date, but also have been adopted by other 73 countries around the world (MASB, 2015). The application of MPERS is however, considered complicated, especially for small micro enterprises. Thus, this problem leads to the research motivation. The research is objectively to investigate the implementation of MPERS on small medium enterprises (SMEs) and how they perceive the implementation.

\section{Literature Review}

The Malaysian Accounting Standards Board (MASB) has launched a new Malaysian Private Entities Reporting Standard (MPERS) financial reporting framework for private entities and several standards of amendments for non-private entities. The MPERS is implemented by all private entities to their financial statements starting on or after $1^{\text {st }}$ January 2016 . The MPERS is simply the IFRS for SMEs released in July 2009 by the International Accounting Standards Board (IASB), in addition to the property development activities requirements and income tax. To date, exceeding 80 countries have implemented or declared plans to do so on the IFRS for SMEs. When the idea was presented and shared in 2013 and globally, one study by Aziz et al. (2019) stated that the transition to MPERS initially faced recognized problems or challenges as a factor in the changes to major global taxation systems, which is, Goods and Services Tax (GST). The MASB issued the MPERS in February 2014 and established a new landmark for private entities financial reporting in Malaysia's. MPERS is based largely on the International Financial Reporting Standard for Small and Medium enterprises (IFRS for SMEs) released in July 2009 by the IASB. Furthermore, in October 2015, MASB issued MPERS amendments in 2016, which are identical to the IFRS amendments issued by IASB in May 2015 for SMEs. The amendments make some minor changes to the requirements of the MPERS, prepare more details or guidance on the requirements and in regulating those standards, comply with those of the MFRS. The amendments apply to financial statements starting on or after 1 January 2017 and are permitted for early implementation. However, in Section One of Private Entities, Section Nine of Consolidated and Separate Financial Statements and Section 34 of Specialized Activities, there were several differences and amendments to the initial IFRS for SMEs. These amendments are important for enhancing the comparability of the standards with the financial statements of small and medium-sized enterprises in other countries and for reducing the sophistication of the standards so that they can be easily adopted by small and medium-sized enterprises and thus provide users with more accurate and usable information (Jamil et al., 2020). The new reporting framework, referred to as the MPERS Framework, is valid for financial statements beginning on or after 1 January2016, allowing for early implementation. As of 1 January 2016, all private entities, as well as small and medium-sized businesses, were compulsory to apply the MPERS when preparing their financial statements. In addition, Salin (2017) reported those who want to adopt PERS and MPERS must follow these standards beginning or ending on 1 January 2016 and ending on or after 1 January 2012 for annual MFRS. Private entities currently have the option of sustaining the existing Private Entity Reporting Standards (PERS) Framework, or implementing the Malaysian Financial Reporting Standards (MFRS) Framework (mandatory for non-private entities, excluding transitional entities), or mandatory shift to the new MPERS System by 1 January 2016. Private entities need to prepare earlier if they expect to move to the MPERS or MFRS framework soon, because the requirement for MPERS to be implemented for the first time is retrospective. A common question that may be raised by private entities is how far or how specific the existing PERS framework is compared to the new MPERS or MFRS framework. Additionally, the MFRS framework may be implemented by private companies who chose not to adopt MPERS. According to Team (2016), SMEs are referring based on Private Entity Reporting Standards (PERS), which are deemed obsolete on the basis of previous International Accounting Standards (IAS) as of 2003. In this context, MASB (2014) mentions private entities are defined as a private entity which was integrated under the 1965 Companies Act. The private entity or company is not a subsidiary or jointly controlled entity or associate of an entity which is expected to submit financial statements in accordance with the rules and regulations of the Securities Commission and of the Central Bank of Malaysia and is not under the jurisdiction of the Securities Commission and the Central Bank of Malaysia. In different study by Sia et al. (2018) 
examined MPERS, as compared to PERS, limits the option of accounting policy and which create dilemmas for those businesses that plan to move to this standard. For example, by using the new borrowing cost method, businesses from Construction and Property Development companies may be impacted because it now has to be classified as expense rather capitalized. The infinite life of their assets must be considered by companies with large intangible assets and the intangible assets must be amortized for 10 years. For example, a plantation business is needed to measure its biological assets at fair value. While investment property undertakings receive additional valuation expenses for those properties.

On the other hand, Prochazka (2017) described the transition to MPERS will be difficult, as the process of change to get it right crucially requires relearning and retraining. Besides, it is also necessary to negotiate on the advantages of switching to MPERS to keep in line with market trends that are not quite as simple from the developer's perspective. Aziz et al. (2019) mention for developers who need to learn how to keep up with being active and versatile, constant adjustment in the conceptual framework is also a problem. Furthermore, the skills lack is also another problem since small and medium-sized companies differ widely in size and this restriction the affordability to look for higher quality accounting services. By contrast, MPERS, has very bit detail and guidelines on implementation, will make it very challenging to compare and may threaten the quality of the framework for financial reporting (i.e., relevance). A number of studies have found that developers in private sector aspect are broadly defined and not finite solely to accounting that could help to broaden the demand for SMP services that SMEs already retain for auditing and other employment (Ametorwo, 2016; Accountants, 2017; Yasser et al., 2017)). The current study had used theories to interpret the research, including the Stewardship Theory, the Agency Theory, and the firm theory's resource-based view.

\section{Small and Medium Enterprises (SMEs) in Malaysia}

In Malaysia, there is no specific explanation of Small and Medium Enterprises (SMEs). Each company defines small and medium enterprises on the basis of its own criteria, typically on the basis of its and number of full-time employees and annual sales turnover. On 14 July 2013, the National SME Development Council (NSDC) propose new SME definition. The definition is simplifying as:

-Sales turnover for manufacturing sectors not surpassing RM50 million or full-time employees not surpassing 200.

-Sales turnover not surpassing RM20 million or full-time employees for services and other sectors not surpassing 75.

In case it meets any one of the two specific qualifying requirements, which is full-time employees or sales turnover whichever is lower, a business will be classified as a SME (SME Corp. Malaysia, 2013). The new definition and explanation of small and medium-sized enterprises (SMEs) in Malaysia by operating size is as follows:

Table 1

Categories of SMEs in Malaysia

\begin{tabular}{|c|c|c|c|}
\hline CATEGORY & MICRO & SMALL & MEDIUM \\
\hline Manufacturing & $\begin{array}{l}\text { Sales turnover } \\
\text { below RM300,000 or } \\
\text { below } \mathbf{5} \text { full-time employees }\end{array}$ & $\begin{array}{l}\text { From RM300,000 to less than } \\
\text { RM15 mill Sales turnover or } \\
\text { full-time employees from } 5 \text { to } \\
\text { below } 75\end{array}$ & $\begin{array}{l}\text { From RM15 mil t } \\
\text { RM50 mil Sales } t \\
\text { employees from } 7\end{array}$ \\
\hline $\begin{array}{l}\text { Services and Other } \\
\text { Sectors }\end{array}$ & $\begin{array}{l}\text { Sales turnover } \\
\text { below RM300,000 or below } \\
\mathbf{5} \text { full-time employees }\end{array}$ & $\begin{array}{l}\text { From RM300,000 to less } \\
\text { than RM3 mil Sales turnover or full- } \\
\text { time employees from } 5 \text { to below } \mathbf{3 0}\end{array}$ & $\begin{array}{l}\text { From RM3 mil to not exceeding } \\
\text { RM20 mil Sales turnover or } \\
\text { full-time employees from } \mathbf{3 0} \text { to below } \\
\mathbf{7 5}\end{array}$ \\
\hline
\end{tabular}

However, if the business meets between one specific qualifying criterion over the varying sizes of operation, the smaller size would be relevant. SMEs are important for the development and growth of the business. It takes a crucial part not only in developing countries but also in developed economies as well (Chiao, 2006). In addition to sustaining national, regional and local economic development, this business group is able to sustain economic growth (Taylor \& Murphy, 2004). In which to try innovation, it is also more flexible to market changes and more determined (Storey, 2016).

\section{Implementation of Malaysian Private Entity Reporting Standard (MPERS) in Malaysia}

Small and medium enterprises (SMEs) are expected to focus entirely on the MPERS by January 2016, a recent version of the standard for financial statement reporting guidelines. MPERS is relevant to all private entities for financial statements beginning on 1 January 2016. MPERS is based on International Financial Reporting Standard (IFRS), which been introduced by the International Accounting Standards Board (IASB) in July 2009 for small and medium-sized enterprises. 
Malaysian version of the IFRS was announced by MASB in Feb 14, 2014, to replace the existing PERS. The previous Private Entity Reporting Standard (PERS) framework was obsolete and therefore Malaysia SMEs will be more competitive in the eyes of foreign investors with revised new practices. With the implementation of MPERS, SMEs will have an efficient financial reporting system which requires one-off cost injection.

Malaysian Institute of Accountants (MIA) and MASB have organized numerous outreach programs to educate SMEs on the aspects and technicality of MPERS for the past two, three years. MPERS will promote greater efficiency among SMEs which will lead to coherent trade and investment. In the light of improved access to financial services, the Chairman of the Financial Reporting Foundation, Tan Sri Azlan Zainol, said the implementation of the MPERS as new Malaysian standards could open up a good deal of business opportunities. It would encourage growth and consequently increase the contribution of SMEs to the economy. The introduction of MPERS would allow financial statements by SMEs more comparable to financial statements by SMEs in at least in 73 countries such as the Hong Kong and United Kingdom. With the exception of the specifications for who associated in property development activities, the MPERS is similar to the IFRS for SMEs set by the IASB.

MPERS implementations would typically relate with strengthen accounting quality and result in more value-added accounting information that is suitable for MPERS. The implementation of MPERS is that it improves financial reporting quality; however, the key problem found in most prior literature is how this consistency can be operationalized and measured. The financial report must be relevance, timeless, understandability, comparability, and reliability to achieve high quality level of financial reporting. One of the studies by Gajevszky (2015) stated, consequently, as a high-quality financial reporting initiative, the focus is therefore on transparent financial reporting and not misleading user financial reporting, not to mention the value of reliability and predictability.

Currently, the issues and problems regarding to the MPERS implementation is due to MASB has not issued a new PERS standard. Previously, PERS provided private entities an alternative way of presenting their annual financial statements in compliance with the international accounting standard. MASB issued PERS based on accounting standards established by the International Accounting Standards Committee up to 2003 and thus obsolete and should be reviewed as a priority. Since then, after 1 January 2006, no new PERS has been issued. Between PERS and the new reporting standard, MPERS, the gap is between 10 to 11 years. PERS framework has not were revised to incorporate changes in the last 11 years, even though the MFRS had made significant adjustments, development and enhancements. IFRS and MFRS are always change but on SMEs it does not change. MASB released MPERS to introduce the improvements to small and medium enterprises (SMEs) and to see the quality of financial statements since the introduction.

\section{Methodology}

The current study used a questionnaire analysis and around 75 enterprises that categorized as micro, small and medium willing to participate. Out of 75 enterprises, only 55 of them responded back to the researcher. The survey was conducted in between March 2020 to June 2020.The study used SPSS software to conduct linear regression analysis. To assure the validity of the questionnaires, a study test on a set of classical assumptions comprising a normality test and a heteroscedasticity test is used. The study also analyzed the quality of data using tests of reliability and validity. As shown below, Table 2 indicates the result.

The research instruments consisted of two parts. Demographic information such as age, education, company type, company size, position, and work experience were covered in the first part. The second part involves of 28 statements; each indicates numerous MPERS factors of SMEs in Malaysia. The question was asked to respondents are on the 5-point Likert scale to illustrate for each those comments, their degree of agreement or disagreement. In addition, as already discussed in the literature review, the research measures are designed on the basis of the factors affecting each variable.

Table 2

Classical Hypotheses and Data Quality Tests Results

\begin{tabular}{lll}
\hline Tests & Results & Conclusion \\
\hline Heteroscedasticity & Asymp Sign. $=0.350$ & Ho accepted \\
Normality & Sig. $=0.864$ & Ho accepted \\
Validity Test & Sig $<0.005$ & Ho accepted \\
Reliability Test & 0.746 & Ho accepted \\
\hline
\end{tabular}

\section{Discussion and Analysis}

From the questionnaire distributed, only 55 enterprises responded back, and the data tested out were in a normal distribution. All measurements of the respondent's perceptions of the implementation of MPERS are accurate and reliable. 
Furthermore, the result showed that the model fulfilled the test for heteroscedasticity and normality. For demographic results, the study shows that there is no significant difference among respondent's perceptions on MPERS implementation. In the current study, additional testing was carried out in which it turned out the age, education, type of companies, company size, position of the respondence, work experience did not indicate significant differences in the respondent's perceptions. Most respondents were men under the age of 45 who operated businesses with less than five years of experience in micro-scale business and high-school education services. From the results, the study indicates they do not understand the technical part of financial reporting standard, including the MPERS.

The result of linear regression analysis indicates that the companies have a very positive impact on the views of MPERS by respondents. The coefficient of regression is 0.215 , the significant is 0.002 and the coefficient of determination of $35.8 \%$ as shown below. Hence, it indicates the companies that fulfilling the criteria of private entities have the ability to make the views of MPERS acceptable by respondents.

Table 3

Analysis of Linear Regression

\begin{tabular}{llllll}
\hline Models & $\begin{array}{l}\text { Unstandardized } \\
\text { Coefficient }\end{array}$ & $\begin{array}{l}\text { Standardized } \\
\text { Coefficient }\end{array}$ & & & \\
\hline & B & Standard Error & Beta & t & Sig \\
\hline Constants & 20.324 & 3.505 & & 5.687 & 0.002 \\
Conditions & 0.215 & 0.043 & 0.467 & 4.398 & 0.002 \\
Adjusted R-square & 0.358 & & & & \\
\hline
\end{tabular}

From the finding, it shows that most of the respondents highlighted that they understood the financial accounting standard, however they have difficulties in terms of preparing financial statements based on the guideline of MPERS. They also stated that the complexities of the standard lead to their misunderstood the technical terms used in the MPERS. However, they agreed that the standard purposely established to improve the financial reporting quality. Janie et al. (2020) conducted a similar study in Indonesia on the application of accounting standards for micro small and medium enterprises in Indonesian which how they perceived the standard. The results indicate that SAK EMKM can be implemented to help prepare financial reports quite quickly and easily.

Furthermore, majority respondents acknowledged that in general, MPERS is not direct and simple to understand and comprehend especially the terms part and jargon used in the standard. Some of the vocabulary used are not understandable and these results suggested that the language of the MPERS could be tone down to increase understanding the general readers. This is compatible with study conducted earlier by Jamil et al. (2020) and Young (2003) on the complexity and extend of technical language used in standard.

In addition, the respondents decided that when implementing the MPERS, they need to refer to and consult with other resources. The other resources include the other companies within the industry, the superior staff, and experts such as accounting firms. The extent of guidance hence leads to the greater cost and effort for the small business during the MPERS implementation. Therefore, this is persistent with previous study performed by Coppens et al. (2007) and Buchanan (2003) on the cost of compliance for SMEs become extra and costly for them. However, when preparing the entity's financial statements, the respondents agree that the implementation of the MPERS will be capable of representing the financial statements and position fairly or reasonably. In addition, it is suggested as well from the result that if the SMEs have sufficient resources to understand the MPERS, hence it would be much easier for the SMEs to prepare the financial report.

\section{Conclusion}

The paper main objective was to investigate the implementation of MPERS for small and medium enterprises (SMEs) in Malaysia and how they perceive the implementation. To provide the insights from the SMEs perspective, the current study has conducted a survey among the SMEs enterprises in Malaysia. Therefore, based on the findings there are few challenges for the SMEs to implement the MPERS though they know the benefits of applying the standards. Among the challenges are the complexity of the standard leads to the technical difficulties, the misunderstanding of MPERS due to the technical language and terms and lack of sufficient resources to refer to that lead to the greater costs and efforts. During these challenging times somehow, they may also present reports of adjustment in financial positions, financial statements, and cash flow. Hence, further investigation needs to be conducted on how these financial statements are generated.

However, there is still a need to highlight the limitations of this study. There are 98.5 per cent business establishments in Malaysia are comprises of SMEs (Jamil et al. 2020). The number of respondents participating in the current study therefore does not reflect 
the actual situation of the implementation of MPERS in Malaysia. Future research on the interview process may be explored to gain an in-depth analysis of the actual implementation of MPERS.

\section{Acknowledgement}

This study is funded by the Malaysian Ministry of Education for FRGS Funding with Code: FRGS/1/2018/SS01/USIM/02/3 and Universiti Sains Islam Malaysia (USIM) with Code: USIM/FRGS/FEM/055002/51518 (Benchmarking Malaysian Private Entity Reporting Standard in Malaysia in Achieving High Income Nation).

\section{References}

Accountants, I. F. O. (2017). Small and Medium Practices. Retrieved 28 May 2017 from https://www.ifac.org/about-ifac/smalland-medium-practices.

Ametorwo, A. M. (2016). Managing work family conflict among female entrepreneurs in Ghana for development. International Journal of Economics, Business and Management Studies, 3(1), 21-35.

Aziz, S. A., Bakar, F. A., \& Latif, R. A. (2019). The readiness and challenges of the Malaysian private entities reporting standard (MPERS). International Journal of Innovation, Creativity and Change, 5(2), 1621-1634.

Buchanan, F. R. (2003). International accounting harmonization: Developing a single world standard. Business Horizons, 46(3), 61-70.

Chiao, Y. C., Yang, K. P., \& Yu, C. M. J. (2006). Performance, internationalization, and firm-specific advantages of SMEs in a newly-industrialized economy. Small Business Economics, 26(5), 475-492.

Coppens, C., Van Wymeersch, K., Van Hecke, A., Engels, L., De Beelde, I., De Lembre, E., ... \& Van De Velde, G. (2007). An investigation into the attitude of Belgian SMEs towards the implementation of IAS/IFRS. In Annual Conference of the European Accounting Association.

Gajevszky, A. (2015). Assessing Financial Reporting Quality: Evidence from Romania. Audit Financiar, 13(121).

Jamil, N. N., Ramli, N. M., Marzuki, A., \& Ahmad, N. N. (2020). Malaysia private entity reporting standard (MPERS) adoption for SMEs: Insights from accounting practitioners in Malaysia. Business and Economic Research, 10(2),104-122.

Janie, D. N. A., Yulianti, Y., Rosyati, R., \& Saifudin, S. (2020). The implementation of Indonesian Accounting Standards for Micro, Small and Medium Entities. Humanities \& Social Sciences Reviews, 8(1), 383-388.

Malaysia, B. N. (2005). SME annual report 2005. Kuala Lumpur.

Malaysian Accounting Standard Board (2015). Malaysian Private Entities Reporting Standards (MPERS).

Procházka, D. (2017). The unintended consequences of accounting harmonization in a transition country: A case study of management accounting of private Czech companies. Contemporary Economics, 11(4), 443-458.

Salin, A. S. A. P. (2017). Malaysian Private Entities Reporting Standards-Benefits and Challenges to SMEs. International Journal of Academic Research in Business and Social Sciences, 7(11), 1302-1320.

Storey, D. J. (2016). Understanding the small business sector. Routledge.

Taylor, M., \& Murphy, A. (2004). SMEs and the take-up of e-business. Urban Geography, 25(4), 315-331.

Team, T. A. T. E. (2016). MPERS - Transforming Small Business Finance. Accountants Today, 29, pp. 16-27.

Yasser, Q. R., Al Mamun, A., \& Rodrigs, M. (2017). Director training and financial disclosure: Asian insights. Contemporary Economics, 11(2), 145-160.

Young, J. J. (2003). Constructing, Persuading and Silencing: The Rhetoric of Accounting Standards. Accounting, and Society, $28(6), 621-38$

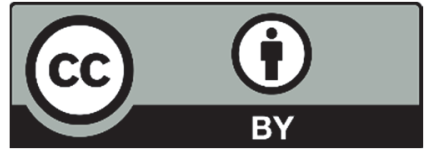

(C) 2021 by the authors; licensee Growing Science, Canada. This is an open access article distributed under the terms and conditions of the Creative Commons Attribution (CC-BY) license (http://creativecommons.org/licenses/by/4.0/). 